\title{
Simulation of Poloidal Divertors in One-Dimensional Tokamak Transport Codes
}

\author{
A. T. Mense \\ G. A. Emmert
}

OAK RIDGE NATIONAL LABORATORY OPERATED BY UNION CARBIDE CORPORATION · FOR THE DEPARTMENT OF ENERGY 


\section{DISCLAIMER}

This report was prepared as an account of work sponsored by an agency of the United States Government. Neither the United States Government nor any agency Thereof, nor any of their employees, makes any warranty, express or implied, or assumes any legal liability or responsibility for the accuracy, completeness, or usefulness of any information, apparatus, product, or process disclosed, or represents that its use would not infringe privately owned rights. Reference herein to any specific commercial product, process, or service by trade name, trademark, manufacturer, or otherwise does not necessarily constitute or imply its endorsement, recommendation, or favoring by the United States Government or any agency thereof. The views and opinions of authors expressed herein do not necessarily state or reflect those of the United States Government or any agency thereof. 


\section{DISCLAIMER}

Portions of this document may be illegible in electronic image products. Images are produced from the best available original document. 


\section{Printed in the United States of America. Available from National Technical Information Service \\ U.S. Department of Commerce \\ 5285 Port Royal Road, Springfield, Virginia 22161 \\ Price: Printed Copy $\$ 5.25$; Microfiche $\$ 3.00$}

This report was prepared as an account of work sponsored by an agency of the United States Government. Neither the United States Government nor any agency thereof, nor any of their employees, contractors, subcontractors, or their employees, makes any warranty, express or implied, nor assumes any legal liability or responsibility for any third party's use or the results of such use of any information, apparatus, product or process disclosed in this report, nor represents that its use by such third party would not.infringe privately owned rights. 
ORNL/TM-6279

Dist. Category UC-20a, d, and $\mathrm{g}$

Contract No. W-7405-eng-26

FUSION ENERGY DIVISION

SIMULATION OF POLOIDAL DIVERTORS IN ONE-DIMENSIONAL

TOKAMAK TRANSPORT CODES

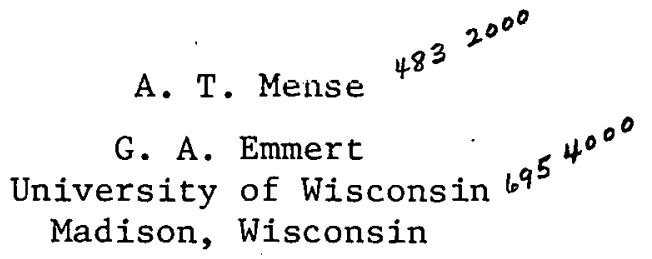

Date Published - April, 1978

This report was prepared as an account of work sponsored by the United States Covemment. Neither the

United States nor the Upited States Danather of

Energy, nor any of their employees, nor any of their

contractors, subcontractors, of their employees,

any warranty, express or implied, or assoyees, makes

liability or responsibility for the aceuncy ans any legal

or usefulness of any information, accuracy, r.mmpirfeness

process disclosed, or represents, that its us, product or

infringe privately owned rights.

i. -

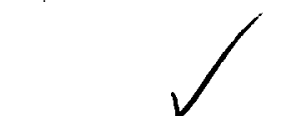

Prepared by the

OAK RIDGE NATIONAL LABORATORY

Oak Ridge, Tennesee 37830

operated by

UNION CARBIDE CORPORATION

for the

DEPARTMENT OF ENERGY 
THIS PAGE

\section{WAS INTENTIONALLY \\ LEFT BLANK}


CONTENTS

ABSTRACT .......................... 1

1. INTRODUCTION ........................ . . . 1

2. SCRAPE-OFF LAYER . . . . . . . . . . . . . . . . . 5

3. TRANSPORT EQUATIONS . . . . . . . . . . . . . . . . . 8

4. BOUNDARY CONDITIONS . . . . . . . . . . . . . . . 11

5. NUMERICAL RESULTS . . . . . . . . . . . . . . 12

5.1 UWAMK-II . . . . . . . . . . . . . 13

5.2 UWMAK-III . . . . . . . . . . . . . . 14

5.3 ASDEX/PDX-SIZE DEVICE . . . . . . . . . . 15

6. A ZERO-DIMENSIONAL DIVERTOR MODEL . . . . . . . . . . 17

7. SUMMARY . . . . . . . . . . . . . . . . . . 25

ACKNOWLEDGMENTS . • . . . . . . . . . . . . . . 26

REFERENCES . . . . . . . . . . . . . . . . . . 27 


\section{SIMULATION OF POLOIDAL DIVERTORS IN ONE-DIMENSIONAL TOKAMAK TRANSPORT CODES}

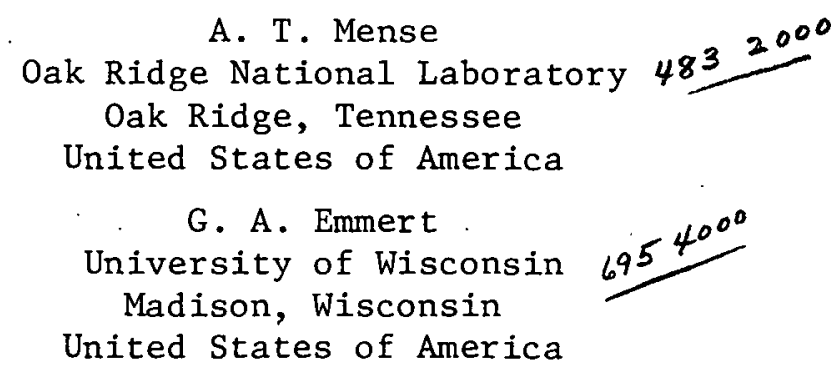

ABSTRACT. The two-dimensional effect of plasma flow along the field lines in the scrape-off zone of a poloidal divertor has been modeled phenomenologically in a one-dimensional tokamak transport code. Some results of the profiles in the scrape-off zone, as well as in the main plasma, are given in this paper. These calculations suggest some approximations, which have been used to develop a zero-dimensional model of the divertor.

\section{INTRODUCTION}

Impurity control in tokamaks appears to be one of the most pressing problems in present-day plasma research and the incorporation of a divertor is a proposed solution [1-4]. The principle of a divertor is to create a region (bounded on one side by a magnetic separatrix and on the other by a liner or vacuum chamber) in which the magnetic field lines are diverted from the local vicinity of the plasma and are channeled into some type of particle collection chamber remote from the plasma. This region of diverted field lines has been appropriately labeled the scrape-off zone. Plasma feeds this zone by diffusion $(\perp \vec{B})$ 
from the plasma core, by ionization of wall and divertor-originated neutrals, and in turn leaves the zone mostly by following field lines to the collection chamber. In this way, the interaction of charged particles with the liner (a source of impurities) can be reduced. The backstreaming of neutrals (and impurities) from the collection chamber into the plasma can be kept small by appropriate design but this remains to be experimentally verified. Using this assumption of small backstreaming as a working hypothesis, one finds a reduction of the neutral population in the plasma boundary. This reduces the bombardment of the liner by energetic charge-exchange neutrals.

Presently there are two operational tokamaks in which divertors have been used. The DIVA [5,6] tokamak has a poloidal divertor (it diverts the poloidal magnetic field), and the DITE [7] tokamak has utilized a bundle divertor (it diverts a flux bundle). Two large poloidal divertor experiments - ASDEX [8] and PDX $[9,10]$ are currently under construction and a similar size device $-(\mathrm{JT}-4$ [111) - has been planined lin Jäpail.

There has been a variety of viewpoints regarding the theoretical predictions of the performance of poloidal divertors. Hinton and Hazeltine [12] have given a neoclassical treatment based on the assumption of hot ions and cold electrons in the scrape-off zone. Boozer [13] has started from the two-fluid Braginskii equations and assumed warm electrons and cold ions. This seems appropriate for the FM-1 [14] and Wisconsin [15] divertor experiments, but is questionable for large tokamaks. A different and somewhat more phenomenological approach has 
been adopted by other workers [16-19]. In these analyses, the twodimensional (2-D) effect of particles flowing along the magnetic field lines to the collectors is simulated in a one-dimensional (1-D) model by an "absorption" term in the particle continuity equation:

$\frac{\partial \mathrm{n}}{\partial t}+\vec{\nabla}_{\perp} \cdot \vec{\Gamma}_{\perp}=-\frac{\mathrm{n}}{\tau_{\|}}$

Here $\Gamma_{\perp}$ is the charged particle flux perpendicular to the magnetic surface, and $\tau_{\|}$is an absorption time constant. According to one's prejudices about the relevant physics in the scrape-off layer, various choices for the perpendicular diffusion coefficient $D_{1}$ (implicit in $\Gamma_{1}$ ) and for $\tau_{\|}$are made. This phenomenological approach has been useful in developing an understanding of the consequences of various physics assumptions and their relative importance in determining divertor operation.

As a consequence of particle flow to the collectors, the particles carry energy away from the scrape-off zone. One anticipates, therefore, that the electron and ion temperatures will drop through the scrape-off zone. Tu cunsider this effect one needs, in addition to Eq. (1), analogous 1-D equations for the electron and ion energy transport. In these equations the energy flow to the collectors is then modeled by an "energy absorption" term. An additional physical process, which may be important, is the possibility that ions may charge exchange with the background neutral gas and thereby produce hot neutral particles which strike the wall. Considering all these effects simultaneously leads to a very complicated and highly nonlinear set of equations. Furthermore 
the boundary conditions to be imposed at the separatrix are very much dependent on the plasma conditions inside the separatrix surface. Consequently, one must resort to numerical techniques and solve the equations for the scrape-off zone simultaneously with the equations for the interior plasma.

The above approach was adopted in the work reported here. We took a tokamak simulation code $[20,21]$, which was based on the code developed at Oak Ridge National Laboratory [22], and assigned some of the mesh points to the scrape-off zone. In this zone the finite-difference transport equations are modified to include particle and energy absorption terms. The perpendicular transport in the scrape-off layer is assumed to be Bohm-1ike but with a variable coefficient. The remaining mesh points are assigned to the interior plasma and treated in the usual way (pseudoclassical, neoclassical, and/or trapped-particle transport coefficients depending on the collisionality of the plasma). Ionization and charge exchange of neutral particles are also treated, but impurities are neglected. 'lhe code determines the temporal evolution of the plasma density, temperatures, and neutral density profiles in the interior zone and in the scrape-off zone, starting from a given set of initial conditions.

In this paper we describe the treatment of the scrape-off layer, discuss in some detail the transport equations which are solved numercially, and then present some results for reactor- and ASDEX/PDX-size devices. Finally, we present a simplified zero-dimensional (0-D) model using approximations suggested by the 1-D numerical result. 


\section{SCRAPE-OFF LAYER}

The processes of cross-field diffusion and parallel transport in the scrape-off layer of a poloidal divertor are 2-D. The multifluid computer codes available are 1-D (the radius in cylindrical coordinates). Hence some assumptions need to be made to reduce the $2-D$ problem to a 1-D one. This is done by the replacement

$$
\begin{aligned}
& \nabla \cdot \vec{\Gamma}=\nabla_{\perp} \cdot \vec{\Gamma}_{\perp}+\nabla_{\|} \cdot \vec{\Gamma}_{\|} \\
& \nabla_{\perp} \cdot \vec{\Gamma}_{\perp}=\frac{1}{r} \frac{\partial}{\partial r}\left(r \Gamma_{\perp}\right)
\end{aligned}
$$

$\mathrm{V}_{\|} \cdot \vec{r}_{\|} \rightarrow\left\{\begin{array}{ll}\frac{\Gamma_{\|}}{\mathrm{L}}=\frac{\mathrm{nV}}{\mathrm{L}}=\frac{\mathrm{n}}{\tau_{\|}}, & \mathbf{r}>\mathrm{r}_{\text {separatrix }} \\ 0 \quad & \mathbf{r}<\mathrm{r}_{\text {separatrix }}\end{array}\right\}$

where $\vec{\Gamma}$ is the particle flux. Here $\mathrm{L}$ is the magnetic field.1ine length from the midplane to the divertor throat and can be a function of $r$. The replacement $\nabla_{\|} \cdot \Gamma_{\|} \rightarrow \Gamma_{\|} / L$ can be thought of as arising from an averaging of $\nabla_{\|} \cdot \Gamma_{\|}$along the field line:

$$
\nabla_{\|} \cdot \Gamma_{\|} \rightarrow \frac{1}{L(r)} \int_{0}^{L(r)} d s \nabla_{\|} \cdot \Gamma_{\|}=\frac{\Gamma_{\|}[L(r)]}{L(r)}
$$

since $\Gamma_{\|}($at $s=0)=0$ by symmetry. 


$$
\begin{aligned}
& \text { We choose } \Gamma_{\|}(L) \text { to be } \\
& \Gamma_{\|}=\iint_{-\infty}^{+\infty} d v_{x} d v_{y} \int_{0}^{\infty} d_{z} v_{z} f_{i}(v)=n(r) \sqrt{\frac{k T_{i}(r)}{2 \pi m_{i}}} \\
& \quad \equiv \frac{n(r) L(r)}{\tau_{\|}(r)}
\end{aligned}
$$

if $T_{i}>T_{e}$. Equation (b) also serves to detine $\pi_{\|}(r)$. 'lihe tlux given in Eq. (5) is the random flux assuming a Maxwellian plasma of density $n$ and temperature $\mathrm{T}_{i}$. If we were to have $\mathrm{T}_{e}>\mathrm{T}_{i}$, then it would be more appropriate to have $\Gamma \simeq \mathrm{nC}_{S}$, where $\mathrm{C}_{S}$ is the ion sound speech, as is well-known from probe theory in cold-ion plasmas [23]. In the calculation presented here, this case does not arise.

For the ion energy flux along the magnetic field, we find

$$
\begin{aligned}
Q_{\|}^{i} & =\int_{-\infty}^{+\infty} \int_{x} d v_{x} d v_{y} \int_{0}^{\infty} d v_{z} \frac{1}{2} m_{i} v^{2} v_{i z} f_{i} \\
& =2 k T_{i} \Gamma_{\|}
\end{aligned}
$$

By requiring the net electrical current at the collector plates to be zero, one can solve for $v_{\max }$, the electron velocity above which electrons are collected by the plate. Using this, one finds for the electron flux

$$
Q_{\|}^{e}=\iint_{-\infty}^{+\infty} d v_{x} d v y \int_{v_{\max }}^{\infty} d v_{z} \frac{1}{2} m_{e} v^{2} v_{z} f_{e}=2 k T_{e} \gamma \Gamma_{\|}
$$


where

$$
\begin{aligned}
\gamma & \equiv 1+\frac{1}{4} \ln \left(\frac{m_{i} T_{e}}{m_{e} T_{i}}\right) \\
v_{\max } & =\sqrt{\frac{k T_{e}}{m_{e}}}\left[\ln \left(\frac{m_{i} T_{e}}{m_{e} T_{i}}\right)\right]^{1 / 2}
\end{aligned}
$$

The factor $\gamma\left(\simeq 2.9\right.$ in hydrogen for $\left.T_{i}=T_{e}\right)$ incorporates the effect of an electrostatic sheath at the collector plates, which reflect most electrons back into the plasma. Only electrons with energy greater than the sheath potential are collected; consequent1y, the average energy lost per collected electron is much greater than $2 \mathrm{kT}_{\mathrm{e}}{ }^{\cdot}$, (The effects of secondary electron emission can easily be included [24], but have been left out of Eq. (7) for simplicity.)

An assumption made in these choices for $\Gamma_{\|}, Q_{\|}^{i}$, and $Q_{\|}^{e}$ is that the distribution function remains substantially Maxwellian along the magnetic field in the scrape-off zone. More specifically, no benefit is given to possible trapping of particles in local magnetic mirrors, which are present in the outside divertor of an UWMAK/ASDEX-type double-nul1 divertor. This possibility has been discussed by Mense, Emmert, and Callen [25] and discounted on the basis of various mirror microinstabilities, which are likely to arise and destroy magnetic trapping by enhanced scattering into the loss cone. Of course the distribution function can't be true Maxwellian, or else there would be no free-energy source for the microinstabilities. The net effect, however, is to cause $\tau_{\|}$to be better approximated by the free-steaming valve - Eq. (5) - and then by the time scale for collisional scattering into the loss cone. 
The cross-field diffusion will be assumed to be Bohm-like,

$\Gamma_{1}=-\mathrm{D}_{1} \nabla_{1} \mathrm{n}$

$D_{1}=F \frac{k T e}{16 e B}$

where $F$ is an arbitrary factor and $F=1$ is full-Bohm diffusion. This choice reflects a belief that low-frequency turbulence (say drift waves) may be present in the divertor because of the strong gradients in $n$ and $T$, and thereby cause Bohm-like scaling of $D_{\perp}$. One might also look at this as determining the consequences of what is generally agreed to be the most pessimistic choice for $D_{1}$, namely Bohm diffusion. It should be noted that this model for cross-field diffusion is locally ambipolar $\left(\Gamma_{\perp i}=\Gamma_{\perp e}\right)$, and consequently, the parallel flow is also locally ambipolar. This is contrary to the work of Boozer [13], who found that the flow is locally nonambipolar. This result, however, is a consequence of his model (two-fluid Braginskii equations with $T_{i}=0$ ) and ordering assumptions. Therefore, his results cannot be applied outside that model.

\section{TRANSPOKT EQUA'IIONS}

The tokamak discharge is represented by a set of time-dependent transport equations for electrons and ions in cylindrical geometry with spatial dependence admitted in the radial direction. Equilibrium solutions are found by evolving these coupled equations until the average plasma parameters and profiles remain sensibly constant. 
The equations to be solved include ion and electron power balance equations, the diffusion equation for the ion density, Faraday's law, Ampere's law; a simplified Ohm's law, and a charge neutrality equation. These equations may be written as follows.

$$
\begin{aligned}
& \frac{\partial n_{i}}{\partial t}=-\frac{1}{r} \frac{\partial}{\partial r}\left(r n_{i} v_{i}\right)+n_{e} n_{0}\langle\dot{\sigma v}\rangle_{I Z}-\frac{1}{2} n_{i}^{2}\langle\sigma v\rangle_{D T} \\
& +\dot{n}_{b}-n_{b} n_{T} \sigma_{D T}\left(v_{b}\right) V_{b}+s_{p}(r, t)-\nabla_{\|} \cdot \vec{\Gamma}_{\|} \\
& \frac{\partial}{\partial t} \frac{3}{2} \mathrm{n}_{i} \mathrm{~T}_{i}=-\frac{1}{\mathrm{r}} \frac{\partial}{\partial \mathrm{r}}\left[\mathrm{r}\left(\frac{3}{2} \mathrm{n}_{i} \mathrm{~T}_{i} \mathrm{~V}_{i}+\tilde{Q}_{i r}\right)\right]-\mathrm{n}_{i} \mathrm{~T}_{i} \frac{1}{\mathrm{r}} \frac{\partial}{\partial \mathrm{r}}\left(\mathrm{rV}_{i}\right) \\
& +P_{e i}+P_{b i}+P_{\alpha i}-P_{c x}-\dot{\nabla}_{\|} \cdot \vec{Q}_{\|}^{i} \\
& \frac{\partial}{\partial t} \frac{3}{2} n_{e} T_{e}=-\frac{1}{r} \frac{\partial}{\partial r}\left[r\left(\frac{3}{2} n_{e} T_{e} V_{e}+\tilde{Q}_{e r}\right)\right]-n_{e} T_{e} \frac{1}{r} \frac{\partial}{\partial r}\left(r V_{e}\right) \\
& -\mathrm{P}_{\mathrm{ei}}+\mathrm{P}_{\Omega}+\mathrm{P}_{\mathrm{be}}+\mathrm{P}_{\alpha \mathrm{e}}-\mathrm{P}_{\mathrm{RAD}}-\mathrm{P}_{\mathrm{IZ}}-\nabla_{\|} \cdot \overrightarrow{\mathrm{Q}}_{\|}^{\mathrm{e}}
\end{aligned}
$$

$\frac{\partial B}{\partial t}=\frac{\partial E}{\partial r}$

$\frac{\partial J}{\partial t}=\frac{1}{\mu_{0}} \frac{1}{r} \frac{\partial}{\partial r}\left(r \frac{\partial E}{\partial r}\right)$

$E=\eta_{\|} \mathrm{J}$

$n_{e}=n_{i}+2 n_{\alpha}+\sum_{j} u_{z j} z_{j}$ 
$\mathrm{T}_{\mathrm{e},(\mathrm{i})}$ is the electron (ion) temperature, $\mathrm{B}_{\mathrm{p}}$ is the poloidal magnetic field, $\mathrm{n}_{e,(i)}$ is the electron (ion) density, $\mathrm{n}_{0}$ is neutral atom density, $n_{b}$ is beam density, $v_{i,(e)}$ is the ion (electron) radial diffusion velocity, $v_{b}$ is the energetic beam velocity, $J$ is the toroidal current density, $E$ is the toroidal electric field, $\eta_{\|}$is neoclassical resistivity, $r$ is the radial coordinate, $t$ is time, $\tilde{Q}_{j r}$ is the thermal conduction of the $j$ th species, $P_{e}$ is the electron-ion equilibration, $\mathrm{P}_{\mathrm{b}(\alpha), i(e)}$ is the beam (alpha) power delivered to the fon (electron) population, $P_{e x}$ is the power loss due to charge exchange, $P_{\Omega}$ is the ohmic heating power, $\langle\sigma \mathrm{V}\rangle_{D T}$ is the fusion rate for background plasma, $\mathrm{P}_{\mathrm{RAD}}$ is the power loss by electromagnetic radiation, $\mathrm{P}_{\mathrm{IZ}}$ is power loss due to ionization of neutrals including impurities (which does not appear in $\mathrm{P}_{\mathrm{RAD}}$ ), $\mathrm{Q}_{\|}^{i,(e)}$ is ion (electron) energy flux parallel to field lines in the scrape-off zone, $\Gamma_{\|}$is the particle flux parallel to the field lines in the scrape-off zone, $\dot{n}_{b}$ is the net rate of density increase due to neutral beam injection, and $S_{p}(r, t)$ is the plasma source due to pellet injection. These equations and the transport codes based on them have been discussed in more detail by Hogan [26] and Düchs [27]. In addition to the above equations, the steady-state Baltzmann transport equation for neutrals is solved to give $n_{0}(r)$. The differential equations for the plasma behavior are solved using a Crank-Nicholson method [28] In which the diffćrchtial cquations arc linẹariżed (In tỉme) and transformed into an implicit set of difference equations $[29,30]$.

The transport coefficients used to compute $V_{i,(e)}, \tilde{Q}_{i,(e) r}$ are treated implicitly and are assumed to vary in functional form as the plasma changes in collisionality. In the calculations reported here, 
the theoretical predictions of microinstability theory [21] (in the form of the so-called five-regime model [31]) have been used. In the divertor zone Bohm-type diffusion has been assumed. The estimated transport coefficients are admittedly only order-of-magnitude estimates, but the assumption is that even rapid diffusion (as predicted by these theories) can provide only a pessimistic model.

Heating of the plasma by $3.5-\mathrm{MeV}$ alpha particles produced from $\mathrm{D}-\mathrm{T}$ fusions has been included with the assumptions that the energy is deposited in the plasma instantaneously and on the same flux surface where the alpha particles are born. (The inclusion of finite-alpha slowing down does not influence the equilibria which we find here.) This is reasonable in a large fusion device unless anomalous alpha loss mechanisms are present. The profile of the alphas within the plasma is obtained by a solution of a diffusion equation, which uses the same transport coefficient as the ions. The rethermalization term, $P_{e i}$, and the fast-ion slowing-down terms are evaluated on the assumption that these processes are classical.

As the central purpose of these calculations is to discern the sole effect of our divertor model, the effects of impurities on the plasma behavior have been neglected.

\section{BOUNDARY CONDITIONS}

The previous sections describe the treatment of the scrape-off zone and the transport code. To complete the specification of the problem, we must impose boundary conditions at the wall. Built into the code are 
the conditions at the center (all fluxes are equal to zero) and the requirement that the fluxes be continuous across the separatrix. The usual procedure in tokamak transport codes is to impose values for $\mathrm{n}$, $\mathrm{T}_{i}, \mathrm{~T}_{\mathrm{e}}$ at the "edge" (in our case, the wall). Fortunately, the presence of sink terms in the scrape-off zone reduces the influence of the wallboundary conditions on the density and temperature profiles away from the wall. If the divertor has a high-unload efficiency, then the flux of particles and energy to the wall is smail, and the wall is effectively decoupled from the interior plasma. If one chooses too high a value for the boundary density (for example), one obtains an inverted density profile $(\mathrm{dn} / \mathrm{dr}>0)$ near the wall; the wall acts as a source of charged particles which become "absorbed" in the scrape-off zone. This inverted profile, which is unphysical, can be removed by reducing the boundary density. Then the procedure is to choose boundary values for $n, T_{i}, T_{e}$ which are low enough to avoid inverted profiles near the wall; the profiles in the interior plasma and in the bulk of the scrape-off zone become insensitive to further reduction in the boundary values. This procedure was used in the calculations presented here.

\section{NUMERICAL RESULTS}

In order to study some of the implications of this divertor model, three tokamak devices were numerically modeled. Those chosen were UWMAK-II [32] and UWMAK-III [33], which are conceptual reactor designs,

* This does not preclude it from simultaneously having a good shielding efficiency. 
and a smaller device characteristic of the ASDEX/PDX size. For all the calculations reported here, a cold ion refueling profile of the form $S(r)=S_{0}\left[1-C(r / a)^{2}\right]$ was used. For the UWMAK studies we used $C=0.5$ and for the ASDEX/PDX studies, $\mathrm{C}=0$. In all cases, the refueling is only in the main plasma $(r<a)$ and not in the scrape-off zone $(r>a)$. A density feedback control algorithm was used to adjust the value of $\mathrm{S}_{0}$ in order to maintain a prescribed average density in the plasma. In addition to this source, $10 \%$ of the plasma collected by the divertor was recycled into the main confinement chamber as wall-originated, 5-eV neutrals.

\subsection{UWAMK-II}

This is a large conceptual reactor design (major radius of $13 \mathrm{~m}$, minor radius of $5 \mathrm{~m}$ ) with a nominal thermal power output of $5000 \mathrm{MW}$. The basic parameters are given in Table I. The cross-field transport in the scrape-off zone was assumed to be Bohm [see Eq. (9)]. The steadystate profiles of $\mathrm{n}_{e}, \mathrm{~T}_{i}$, and $\mathrm{T}_{e}$ in the main plasma and in the scrapeoff zone are shown in Figs 1-3. We see in Fig. 1 that the separatrix density is quite small, but also that it is broad enough so that the neutral density is sharply attenuated in the scrape-off zone. Consequently, the charge-exchange neutral flux hitting the wall has an energy spectrum reflecting the ion temperature in the scrape-off zone. $\mathrm{T}_{i}$ at the separatrix (Fig. 3) tends to be high because of the low density there. We also see in Fig. 3 the sharp drop of the electron 
temperature in the scrape-off zone. This is because of the sheath potential effect on $Q_{\|}^{e}$, as noted in Section 2.

In this calculation, the line integral of the electron density through the scrape-off zone is sufficient to shield impurities from the main plasma. Given an isotropic source of $20-\mathrm{eV}$ carbon impurities leaving the wall, $95 \%$ will be ionized in the scrape-off zone. The probability of the impurity ion then diffusing into the main plasma before being captured by the divertor collection chambers is a separate problem requiring more knowledge about impurity transport.

Shown also in Fig. 3 are the alpha density and production rate. Note that about $90 \%$ of the $3,5-\mathrm{MeV}$ alpha particles are born within $2 \mathrm{~m}$ of the center. Energetic alpha particles on large banana orbits intersecting the wall do not present a problem in this size device because so few alpha particles are born near the edge. Furthermore, fluctuations of the "edge" density and temperature do not cause power fluctuations. This has been confirmed recently in discrete pellet injection calculations [34].

\subsection{UWMAK-III}

This reactor design is a smaller (but vertically elongated) and high power density version of UWMAK-II. The basic parameters are also given in Table $I$. In the 1-D transport code, it is modeled as having circular cross section with an effective radius $a_{\text {eff }}=\sqrt{a b}$. However the transport coefficients incorporate, to some extent, the effect of vertical elongation. The steady-state profiles of $n, T_{i}, T_{e}$ are shown 
in Figs 4-6. The results are much the same as for the UWMAK-II ca1culation. In Figs 4 and 6 we show explicitly the effect of neutral particle recyling on the plasma density and ion temperature in the scrape-off zone. The effect is substantial, especially on the ion temperature.

\subsection{ASDEX/PDX-SIZE DEVICE}

Finally, we have performed calculations simulating a poloidal divertor in an ASDEX/PDX-size device. These calculations were done in the same manner as the UWMAK calculations but using a different-code, the WHIST code $[35,21]$. This code is an offshoot of the first one. The WHIST code has the advantage of allowing one to use a nonuniform spatial mesh. We could then use a finer mesh in the scrape-off zone, where the gradients are strong, without a large increase in the total number of mesh points or in the computation time. It also has the advantage of being written with a variable implicit factor. A gain in numerical stability can be obtained by using a fully implicit procedure rather than the Crank-Nicolson. This causes some loss of accuracy in a transient state, but the equilibrium profiles are virtually the same $[35,21]$. The version of the WHIST code used has no equation for diffusion of the poloidal magnetic field; instead the current density profile is prescribed. We used $J(r)=J_{0}\left[1-(r / a)^{2}\right]^{2}$.

The basic parameters used are given in l'able Il. The diffusion coefficient in the scrape-off zone was taken to be equal to the full Bohm value. Neutral particles were not included, but a source of cold 
ions (perhaps due to fueling via pellets or cluster injection) was included to hold the average density constant. The profile for the cold ion source was chosen to be uniform over the plasma inside the separatrix and zero outside. No auxiliary heating was used. Shown in Figs 7 and 8 are the density and temperature profiles in the interior zone and in the scrape-off zone. The results are qualitatively the same as for the reactor cases, although the density at the separatrix and its integral $\left(\int \mathrm{n} d \mathrm{x} \sim 1.5 \times 10^{12}\right)$ across the scrape-off layer are much lower. An interesting result is that, because of the divertor, the plasma spans all the collisionality regimes (for trapped particle instabilities [21]) between the centerline and the separatrix. The low value for the line integral of $n(r)$ in the scrape-off zone implies that there will be no shielding of the interior plasma from incident impurities by the scrapeoff plasma. One can get shielding if the average density is much higher or if the refueling source is peaked near the edge. As a final note one must address numerical problems.

A difficulty in all of these calculations is that the time conseant for flow into the divertor is much shorter than the time constant for the transport processes in the main plasma. As a consequence the scrapeoff plasma is in a state of quasi-equilibrium with respect to the main plasma. The numerical procedure used, however, treats both zones equally as an initial-valued problem. Consequentiy the time step is, to some extent, limited by the short time scale for the scrape-off zone. Other techniques, suitable for handling "stiff" equations, may be superior to the approach used here. 


\section{A ZERO-DIMENSIONAL DIVERTOR MODEL}

From the 1-D analysis just described one notes a number of general features, particularly in the reactor cases (UWMAK-II and -III). These observations which are listed below have lead to the development of a useful 0-D divertor model. The important features which need to be considered are:

(1) The charged-particle flux at the wall is negligible in comparison to the ion flux crossing the separatrix.

(2) The energetic particles bombarding the wall are primarily chargeexchange neutral particles.

(3) The cold neutral particle density at the separatrix is negligible in comparison to the cold neutral density at the wall; marginally satisfied in the ASDEX/PDX case.

(4) The energetic neutrals that reach the wall are "born" primarily in the scrape-off zone.

These four observations are not all independent. Statement 2 is a consequence of 1 , and statement 4 is a consequence of 3 . These observations seem to be general properties of large divertor tokamaks and are not highly dependent on the particular assumptions about the transport processes. Therefore, we are led to consider them to be "universal" and treat them as "axioms" on which to base our model.

The observations 1 through 4 suggest that the scrape-off layer acts as a boundary layer for neutral particles. Backstreaming of cold neutrals from the collection chambers produces a cold neutral population. The 
loss mechanism which balances the neutral source is ionization. Charge exchange of entering neutrals produces a hot neutral population and determines the energetic particle flux bombarding the wall.

We use a slab model for the scrape-off zone. The separatrix is at $\mathrm{x}=0$, and the wall is at $\mathrm{x}=\mathrm{d}$. The neutral particles are placed in two energy groups: "cold" (with temperature $\mathrm{T}_{0}$ ) and "hot" (with temperature equal to the ion temperature $\mathrm{T}_{i}$, where they are born). The "cold" temperature $\mathrm{T}_{0}$ can be taken to be the Franck-Condon energy, although we need not specify it as long as $T_{0} \ll T_{i}$. The plasma density $n$, ion temperature $\mathrm{T}_{i}$, electron temperature $\mathrm{T}_{e}$, and the cold neutral density $\mathrm{n}_{c}$ are assumed to satisfy the following conservation equations.

$$
\begin{aligned}
& \frac{\partial \Gamma}{\partial x}=-\frac{n}{\tau_{\|}}+n_{c}\langle\sigma v\rangle_{I Z} \\
& \frac{\partial \Gamma_{c}}{\partial x}=-n_{c}<\sigma v{ }_{T O T} \\
& \frac{\partial Q_{i}}{\partial x}=-\frac{\gamma_{i}{ }^{n T}}{\tau_{\|}}-2 \alpha \alpha_{E} n_{c}\left\langle\sigma v{ }_{c x} T_{i}\right. \\
& \partial Q_{e}=\gamma_{e}{ }^{n T} \\
& \partial x
\end{aligned}
$$

Here $\Gamma$ and $\Gamma_{c}$ are the flux of ions and cold neutrals, respectively, whereas $Q_{i}$ and $Q_{e}$ are the ion and electron energy fluxes. The reaction rates for ionization and charge exchange are $\langle\sigma v\rangle_{I Z}$ and $\langle\sigma v\rangle_{c x}$, respectively, and $\langle\sigma v\rangle_{\mathrm{TOT}}=\langle\sigma \mathrm{V}\rangle_{\mathrm{IZ}}+\langle\sigma \mathrm{V}\rangle_{\mathrm{Cx}}$. In Eq. (17) we neglected ionization of hot neutrals since $n(h o t) \ll n_{c}$, at least near the boundary. 
The first terms on the right side of Eqs (19) and (20) represent energy flow to the particle collectors. The coefficients $\gamma_{i}$ and $\gamma_{e}$ are dependent on the parallel transport processes assumed to be present. The second term on the right side of Eq. (19) represents the flow to the wall due to charge exchange in the scrape-off zone. Here $1-\alpha_{E}$ is the energy reflection coefficient [36], and $\alpha$ has the following meaning - "For each first generation hot neutral produced in the plasma, $\alpha$ hot neutrals eventually escape and strike the wall." A two generation approximation for $\alpha$ is

$\alpha=\frac{1}{2}\left\{1+\frac{1}{2}\left[1 / 1+\left(\langle\sigma v\rangle_{\mathrm{IZ}}^{\mathrm{H}}\right) /\left(\langle\sigma \mathrm{v}\rangle_{\mathrm{cx}}^{\mathrm{H}}\right)\right]\right\}$

In Eq. (21) the reaction rates are evaluated at $T$ (neutral) $=T_{i}$, whereas in Eqs (17)-(19) the reaction rates are for the cold neutrals.

In accordance with our "axioms" 1-4, we impose the following boundary conditions on Eqs (17)-(20).

$$
\begin{gathered}
x=0: \quad \Gamma=\Gamma(0), Q_{i}=Q_{i}(0), Q_{e}=Q_{e}(0), \Gamma_{c}=0 \\
x-d: \quad \Gamma=Q_{i}=Q_{e}=0 \\
\Gamma_{c}(d)=-R \int_{0}^{d} \frac{n d x}{\tau_{\|}}-\alpha_{p} \Gamma \text { (hot) }
\end{gathered}
$$

where $\Gamma$ (hot) is the hot neutral flux incident on the wall and $1-\alpha_{p}$ is the particle reflection coefficient at the wall [36]. $\Gamma$ (hot) is given by 
$\Gamma($ hot $)=\alpha \int_{0}^{\mathrm{d}} \mathrm{nn}_{\mathrm{c}}\langle\sigma \mathrm{v}\rangle{ }_{\mathrm{cx}} \mathrm{dx}$

In Eq. (23) the first term on the right describes the effect of neutral gas backstreaming from the collection chambers, regarded as a particle source at the boundary. One can also treat it as a distributed volume source in $\mathrm{Eq}$. (18). It is easy to show that there is no difference between these two approaches within the context of this analysis.

The temperature dependence in Eqs (17)-(24) occurs Implicitly in $\langle\sigma v\rangle$ as well as explicitly. Fortunateily the dependence of $\langle\sigma v\rangle$ on temperature is not strong for the values of interest. Hence we replace $\mathrm{T}_{i}$ and $\mathrm{T}_{\mathrm{e}}$ in $\langle\sigma v\rangle$ by spatial averages $\left\langle\mathrm{T}_{i}\right\rangle$ and $\left\langle\mathrm{T}_{e}\right\rangle$, to be defined 1ater. With this approximation, we integrate Eqs (17) and (18) from $\mathrm{x}=0$ to $\mathrm{x}=\mathrm{d}$ and apply the boundary conditions of Eqs (22)-(24) to get

$$
\int_{0}^{d} n_{c} d x=\frac{R \Gamma(0)}{\langle\sigma v\rangle T U T^{D}}
$$

$\mathrm{D}=1-\alpha \alpha_{\mathrm{P}} \frac{\langle O \mathrm{~V}\rangle_{\mathrm{CX}}}{\langle\sigma \mathrm{V}\rangle_{\mathrm{TOT}}}-\mathrm{R} \frac{\langle U \mathrm{~V}\rangle_{I Z}}{\langle\sigma \mathrm{V}\rangle_{\mathrm{TOT}}}$

$\Gamma($ hot $)=\frac{\alpha R \Gamma(0)}{D} \frac{\text { suv } \mathrm{cx}}{\left\langle\sigma v{ }_{\mathrm{TOT}}\right.}$

$$
\int_{0}^{\mathrm{d}} \frac{\mathrm{n}}{\tau_{\|}} \mathrm{dx}=\Gamma(0)\left(1+\frac{\mathrm{R}\langle\sigma \mathrm{v}\rangle}{\mathrm{IZ}}\right)
$$


The second term on the right side in Eq. (19) is of order R, compared with the first term. If the recycling coefficient $R$ is small (say $\sim 10^{-1}$ ), then the second term is not very important, and we can replace

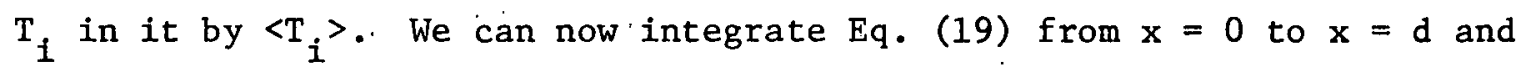
use $\mathrm{Eq} \cdot(25)$ to obtain

$Q_{i}(0)=\int_{0}^{d} \frac{\gamma_{i} n T}{\tau_{\|}} d x+\frac{2 \alpha \alpha_{E}\left\langle T_{i}\right\rangle}{D} \frac{R \Gamma(0)}{\langle\sigma V\rangle_{T O T}}$

We now define

$<\mathrm{T}_{i}>=\frac{\int_{0}^{\mathrm{d}}\left(\mathrm{nT}_{i} / \tau_{\|}\right) \mathrm{dx}}{\int_{0}^{\mathrm{d}}\left(\mathrm{n} / \tau_{\|}\right) \mathrm{dx}}$

and use Eq. (28) to get

$\left\langle\mathrm{T}_{i}\right\rangle=\frac{\mathrm{Q}_{i}(0)}{\gamma_{i} \Gamma(0)\left[1+(\mathrm{R} / \mathrm{D})\left(\langle\sigma \mathrm{v}\rangle{ }_{\mathrm{IZ}}+2 \alpha \alpha_{\mathrm{E}}{ }^{\langle\sigma \mathrm{v}\rangle}{ }_{\mathrm{cx}} / \gamma_{i}\right) /(\langle\sigma \mathrm{v}\rangle)_{\mathrm{TOT}}\right]}$.

Integrating Eq. (20) and using Eq. (28) gives



Recall that the reaction rates are evaluated with $\mathrm{T}_{i, e}$ replaced by $<T_{i, e}>$. Hence Eqs (30) and (31) are to be solved simultaneously for $\left\langle\mathrm{T}_{\mathrm{i}}\right\rangle$ and $\left\langle\mathrm{T}_{\mathrm{e}}\right\rangle$. Since $\mathrm{R}$ is presumably small, this can be done rather easily in an iterative fashion. 
Given the solutions for $\left\langle\mathrm{T}_{\mathbf{i}}\right\rangle$ and $\left\langle\mathrm{T}_{e}\right\rangle$, we can compute the hot chargeexchange neutral particle flux at the wall from Eq. (27); we also assign the temperature $\left\langle\mathrm{T}_{i}\right\rangle$ to these neutrals. It is interesting to note that these results are independent of the mechanism for cross-field ion transport in the scrape-off zone (as long as "axiom 1 " is not violated). The results are only weakly dependent on the parallel transport mechanism through the coefficients $\gamma_{i}$ and $\gamma_{e}$.

The remaining parameter of interest is the effectiveness of the scrape-off layer plasma in ionizing wall-originated impurities. The probability $P$ of an impurity atom traversing the scrape-off layer without ionization depends on the parameter $\beta$,

$\beta=\frac{\langle\sigma v\rangle}{v_{0}} \int_{0}^{d} n d x$

where $\langle\sigma v\rangle_{i m p}$ is the ionization rate and $v_{0}$ is the velocity of the impurity atom. The probability $\mathrm{P}$ also depends on the angular velocity distribution of the incident atoms. For normal incidence $P=e^{-\beta}$, for a cosine distribution $P=2 \mathrm{E}_{3}(\beta)$, and for an isotropic distribution $P=E_{2}(\beta)$, where $E_{2}$ and $E_{3}$ are the exponential integrals [37]. Hence we need $\int_{0}^{d} n d x$ to evaluate $P$. Unfortunately our analysis only gives us $\int_{0}^{d} n / \tau_{\|} d x$. We need to specify a model for $\tau_{\|}$and then estimate a mean value for $\tau_{\|}$. Hence

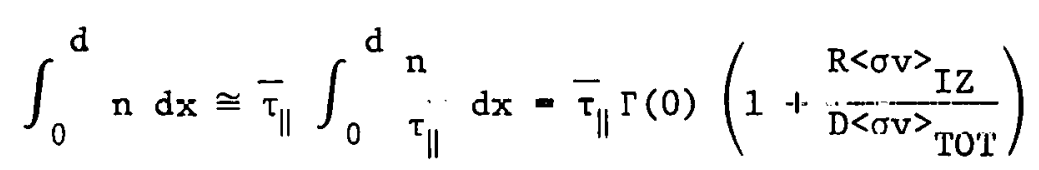


For the ion-sound model with $\mathrm{T}_{i}>\mathrm{T}_{\mathrm{e}}$

$\bar{\tau}_{\|} \cong L \sqrt{\frac{2 \pi M_{i}}{\left\langle\mathrm{~T}_{i}\right\rangle}}$

where $L$ is the field $i$ ine length and $M_{i}$ is the ion mass. The dominant contribution to $\int_{0}^{\mathrm{d}} \mathrm{n} \mathrm{dx}$ is $\tau_{\|} \Gamma(0)$ and has been obtained earlier by Keilhacker [8]. The second term on the right side of Eq. (27) represents the increase in $\int_{0}^{\mathrm{d}} \mathrm{n} \mathrm{dx}$ due to ionization of neutral atoms. This is an effect of order $R$ and hence is small. It is small even if $R \sim 1$, since $\mathrm{D} \cong 0.5$ and $\langle\sigma \mathrm{V}\rangle_{\mathrm{IZ}} \ll\langle\sigma \mathrm{V}\rangle_{\mathrm{TOT}}$ for temperatures anticipated in the scrapeoff zone.

It is worthwhile to repeat some of the assumptions on which this model is based. We have used some observations from numerical calculations as a basis for our model. In these, the assumption most questionable for divertor tokamaks of ASDEX/PDX size is that the scrape-off layer plasma is opaque to cold neutrals. If this assumption is not true, we can define a distance $\lambda$ (measured from the separatrix) beyond which few cold neutrals penetrate. If $\lambda$ is not too large, we can apply our analysis to the zone $-\lambda<\mathrm{x}<\mathrm{d}$ and define $\tau_{\|}=\infty$ for $-\lambda<\mathrm{x}<0$. The results are formally identical except that $\Gamma(0) \rightarrow \Gamma(-\lambda) \approx \Gamma(0)$ and $Q(0) \rightarrow Q(-\lambda) \approx Q(0)$. In this case, the weakest element is probably the ion energy equation. Our definition of $\left\langle\mathrm{T}_{i}\right\rangle$ gives us a value near the separatrix temperature, whereas the charge-exchange neutrals are now coming from deeper within the plasma and therefore have $\mathrm{T}$ greater than $\left.<\mathrm{T}_{i}\right\rangle$. This model then underestimates the temperature of the chargeexchange neutrals striking the wall. This, however, has only a minor 
effect on the flux $\Gamma$ (hot), since the cross sections are relatively insensitive to $\mathrm{T}_{i}$.

A second limitation is that we have neglected the ionization of hot neutrals in the scrape-off zone. This becomes more important in larger tokamaks, especially if we can make $\tau_{\|}$longer than that given by the ion-sound model. This effect produces a correction of order $R$ in $\left\langle T_{i}\right\rangle$ and $\int_{0}^{d} n / \tau_{\|} d x$ and of order $R^{2}$ in $\Gamma(h o t)$, and thus becomes more important with increased recycling. Cencralizing the model to consider this is nontrivial, however, and is not considered here.

As a check on the above analysis we compare its predictions with the results from the more detailed 1-D calculations. This is shown in Table I for the UWMAK-II' and -III cases. For these calculations, the ion-sound model for $\tau_{\|}$has been used. The values listed above for $\left\langle\mathrm{T}_{i}\right\rangle$ using the 1-D calculations are actually the ion temperature at the separatrix. Because of the density weighting factor in Eq. (14), <T $\rangle^{>}$ is close to, but less than, the separatrix temperature. The agreement for $\left\langle T_{i}\right\rangle$ and $\Gamma(h o t) / \Gamma(0)$ is good. The agreement between the 1-D and O-D calculations of $\int \mathrm{n} d x$ is also considered good. In Eq. (32) the term involving the ionization of neutrals is small. Hence the disagreement between the $O-D$ and $1-D$ results has to be attributed to the estimation of $\bar{\tau}_{\|}$. The 1-D code uses a variable $L(r)$ obtained from a magnetic tield code. In the U-D estimate of $\bar{\tau}_{\|}$[Eq. (33)] a single value of $L$, typical of what an ion experiences in the scrape-off zone, is used. Since $L(r)$ is singular at the separatrix and also the density is greatest there, a disagreement by a factor of two between the $0-D$ and 1-D results is not surprising. 
The primary factor determining the hot charge-exchange flux at the wall is the recycling coefficient $R$. In the above results, the value $R=0.1$ has been used for computational purposes. We have made no attempt to estimate $\mathrm{R}$ for a specific design, so the numerical values for $\Gamma(h \circ t)$ presented here are not to be taken literally. The scaling of $\Gamma$ (hot) with $R$ from this model is clear; however, reducing $R$ reduces $\Gamma$ (hot). This conclusion can be modified, however, depending on the refueling mechanism used to maintain constant density. If the refueling mechanism introduces a large number of neutrals into the scrape-off layer, then this will increase $\Gamma$ (hot). This has been considered to some extent by Haas and Keilhacker [8] for ASDEX.

\section{SUMMARY}

The inclusion of the effect of flow along the field line in the scrape-off zone as absorption terms in a 1-D tokamak fluid transport code provides a useful tool for studying the effect of the divertor on the main plasma and on the plasma-wall interaction. We have presented some results where the refueling is spread over the plasma cross section and the neutral gas recycle from the collection chambers is low. The numerical results have been used as a basis on which to formulate a 0-D model of the divertor, which includes the neutral gas interaction as a dominant process. This model shows good agreement with the numerical results and is suitable for coupling with global models for the main plasma. 


\section{ACKNOWLEDGFMENTS}

Some of what has been presented here is from the $\mathrm{Ph} . \mathrm{D}$. thesis work of the first author (A.T.M.). The help and advice from the second author (G.A.E.) and from Dr.H. K. Forsen is gratefully acknowledged. Part of this work was performed while the second author (G.A.E.) was a guest scientist at the Max-Planck-Institute für Plasmaphysik, Garching, FRG. Their hospitality is gratefully acknowledged. 'l'his research was pertormed at the University of Wisconsin and supported by the Wisconsin Electric Utilities Research Foundation and by the U.S. Department of Energy under Contract No. ET-76-S-02-2272. The manuscript was prepared by the Oak Ridge National Laboratory, operated by Union Carbide Corporation for the U.S. Department of Energy under Contract No. W-7405-eng-26. 
REFERENCES

[1] EMMERT, G. A., MENSE, A. T., DONHOWE, J. M., in Technology of Controlled Thermonuclear Fusion (Proc. 1st Topical Meeting San Diego, 1974); J. Nucl. Mater. 53 (1974) 39.

[2] KITSUNEZAKI, A., MAEDA, H., SHIMOMURA, Y., YOSHIKAWA, M., in Toroidal Plasma Confinement (Proc. 3rd Int. Symp. Garching, FRG, 1973) G 2 .

[3] COLVEN, C., GIBSON, A., STOTT, P. E., in Controlled Fusion and Plasma Physics (Proc. 5th Europ. Conf. Grenoble, 1972) 1 (1972) 6.

[4] PDX, The Poloidal Divertor Experiment, in Large Tokamak Designs (Proc. Joint EURATOM - US Workshop, Culham, Oxon, U.K. 1974) 47.

[5] SUZUKI, $\mathrm{Y}_{\bullet}$, in Plasma Wall Interaction (Proc. Int. Symp. Jülich, FRG, 1976) 75 .

[6] MAEDA, H., et al., in Plasma Wall Interaction (Proc. Int. Symp. Jülich, FRG, 1976) 537.

[7] STOTT, P. E.; et al., in Plasma Wall Interaction (Proc. Int. Symp. Jülich, FRG, 1976) 39 .

[8] HAAS, G., KEILHACKER, M., in Plasma Wall Interaction (Proc. Int. Symp. Jülich, FRG, 1976) 691.

[9] MEADE, D. M., in Plasma Wall Interaction (Proc. Int. Symp. Jülich, FRG, 1976) 21 .

[10] MEADE, D. M., SINNIS, J. C., in Plasma Wall Interaction (Proc. Int. Symp. Jülich, FRG, 19.76) 683 .

[11] KITSUNEZAKI, A., et al., in Plasma Wall Interaction (Proc. Int. Symp. Jülich, FRG, 1976) 697. 
[12] HINTON, F. L., HAZELTINE, R. D., Phys. Fluids 17 (1974) 2236.

[13] BOOZER, A. H., Phys. Fluids 19 (1976) 1210.

[14] HSUAN, S., OKABAYASHI, M., EJIMA, S., Nuc1. Fusion 15 (1975) 191.

[15] Strawitch, C. M., emmert, G. A., Bull. Am. Phys. Soc. 21 (1976) 1150.

[16] KEILHACKER, M., Magnetic Divertors, in Tokamak Reactors for Breakeven (Proc. Int. School of Fusion Reactor Technology, Erice, Italy, 1976) Pergamon Press, Oxford, England (1978).

[17] MEADE, D. M., FURTH, H. P., RUTHERFORD, P. H., SEIDL, F. G. P., DÜCHS, D. F., in Plasma Physics and Controlled Nuclear Fusion Research (Proc. 5th. Int. Conf. Tokyo, Japan, 1974) IAEA, Vienna, 1 (1975) 605 .

[18] BADGER, B., et al., "UWMAK-I, a Wisconsin Toroidal Fusion Reactor Design," University of Wisconsin Nuclear Engineering Dept,, Madison, 1974, UWFDM-68, 1 .

[19] STEPHANOVSKII, A. M., "On the Screening of Plasma by Various Divertor Sheaths," Kurchatov Institute Report IAE-2540 (1975) (in Russian).

[20] CONN, R. W., KESNER, J., J. Nucl. Mater. 63 (1976) 1-14.

[21] HOULBERG, W. A., CONN, R. W., Nuc1. Sci. Engr. 64 (1977) 141.

[22] MUNRO, J. K., HOGAN, J. T., HOWE, H. C., ARNURIUS, D. E., Oak Ridge Nationa $\perp$ Laboratory Report ULNL/'IM-5662 (19//).

[23] CHEN, F. F., Introduction to Plasma Physics, Plenum Press, New York (1974) 246. 
[24] MENSE, A. T., University of Wisconsin Ph.D. Thesis, Nuclear Engineering Dept., 1977. A limited number of copies of the above thesis is available upon request as UWFDM-219.

[25] MENSE, A. T., EMMERT, G. A., CALlen, J. D., Nuc1. Fusion 15 (1975) 703.

[26] HOGAN, J. T., "Multifluid Transport Codes" in Methods of Computational Physics (KILlEEN, J., Ed.), Academic Press, New York 16 (1976).

[27], DÜCHS, D. F., POST, D. E., RUTHERFORD, P. H., Nucl. Fusion 17 (1977) 565-609.

[28] CRANK, J., NICHOLSON, P., Proc. Cambridge Philos. Soc. 42 (1946) and 43 (1947).

[29] WIDNER, M. M., DORY, R. A., Bull. Am. Phys. Soc. 11 (1970) 1418 .

[30] HOGAN, J. T., Oak Ridge National Laboratory Report ORNL/TM-5153 (1975) .

[31] DEAN, S. 0., et al., status and Objectives of Tokamak Systems for Fusion Research, USAEC Report WASH-1295 (1974).

[32] BADGER, B., et al., "UWMAK-II, a Conceptual Tokamak Power Reactor Design," UnIverslly uf Wisculsisil Nuclear Engineering Dept., Madison, 1975, UWFDM-112.

[33] BADGER, B., et al., "UWMAK-III, a Noncircular Tokamak Power Reactor Design," University of Wisconsin Nuclear Engineering Dept., Madison, 1976, UWFDM-150.

[34] MENSE, A. T., HOULberg, W. A.; ATtEnBERGER, S. E., Milora, S. L.; Oak Ridge National Laboratory Report ORNL/TM-6026 (1978). 
[35] HOULBERG, W. A., University of Wisconsin Ph.D. Thesis, Nuclear Engineering Dept., 1977.

[36] OEN, O., ROBINSON, M. T., J. Nuc1. Mater. 63 (1976) 210.

[37] ABRAMOWITZ, M., STEGUN, I. A., National Bureau of Standards, AMS- 55 . 
TABLE I. PARAMETERS OF THE DEVICES

\begin{tabular}{lccc}
\hline & UWMAK-II & UWMAK-III & ASDEX/PDX/JT-4 \\
\hline Major radius (m) & 13 & 8.1 & 1.65 \\
Minor radius (m) & 5 & $2.7^{a}$ & 0.40 \\
Vertical elongation (b/a) & 1 & 2 & 1 \\
Plasma current (MA) & 13 & 15.6 & 0.45 \\
Toroidal fiel.d (kG) & 36 & 40 & 28 \\
Working gas & D-T & D-T & H \\
Average density & $5 \times 10^{13}$ & $9 \times 10^{13}$ & $4.2 \times 10^{13}$ \\
\hline Horizontal. & & &
\end{tabular}


TABLE II. COMPARISON OF O-D and 1-D CALCULATIONS

\begin{tabular}{llll}
\hline & Design & $1-\mathrm{D}$ & $0-\mathrm{D}$ \\
\hline$<\mathrm{T}_{\mathrm{i}}>(\mathrm{keV})$ & UWMAK-II & 4 & 3.1 \\
& UWMAK-III & 3.4 & 3.2 \\
$\Gamma(\mathrm{hot}) / \Gamma(0)$ & UWMAK-II & 0.04 & 0.12 \\
& UWMAK-III & 0.14 & 0.12 \\
$\int_{U}^{\mathrm{d}} \mathrm{n} \mathrm{dx}\left(\mathrm{cm}^{-2}\right)$ & UWMAK-II & $1.2 \times 10^{13}$ & $6.3 \times 10^{12}$ \\
& UWMAK-III & $2.6 \times 10^{13}$ & $1.2 \times 10^{13}$ \\
\hline
\end{tabular}


FIGURE CAPTIONS

FIG. 1. UWMAK-II density profile, neutral profile, and carbon impurity deposition profile.

FIG. 2. Profile of origin of charge-exchange neutral flux incident onto first wall. Shielding efficiency, $n_{z}$, is $95 \%$ for $20 \mathrm{eV}$ carbon atoms.

FIG. 3. Temperature profiles for UWMAK-II. Alpha particle birth profile and equilibrium density profile.

FIG. 4. UWMAK-III density profile. Note the effect of recycling $10 \%$ of divertor collected plasma back to main plasma as wall originated neutrals.

FIG. 5. Origin of charge-exchange flux in UWMAK-III.

FIG. 6. Temperature profiles in UWMAK-III. Note effect of $10 \%$ neutral recycling.

FIG. 7. Density profiles for experimental device. Note that the assumed cold fuel fueling profile was taken to be a constant across plasma volume.

FIG. 8. Temperature profile for experimental device. 


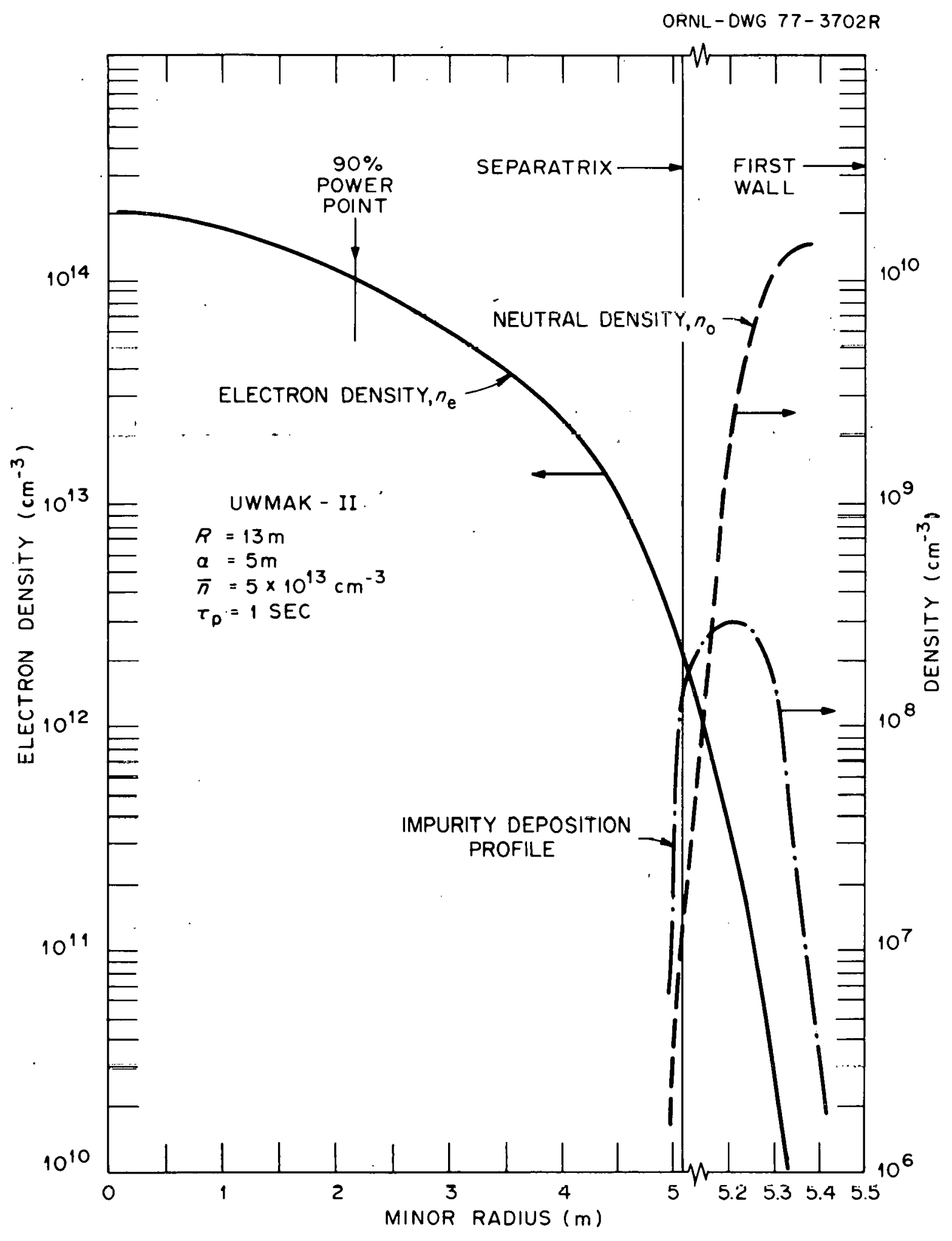

Fig. 1. 
ORNL-DWG 76-8016R

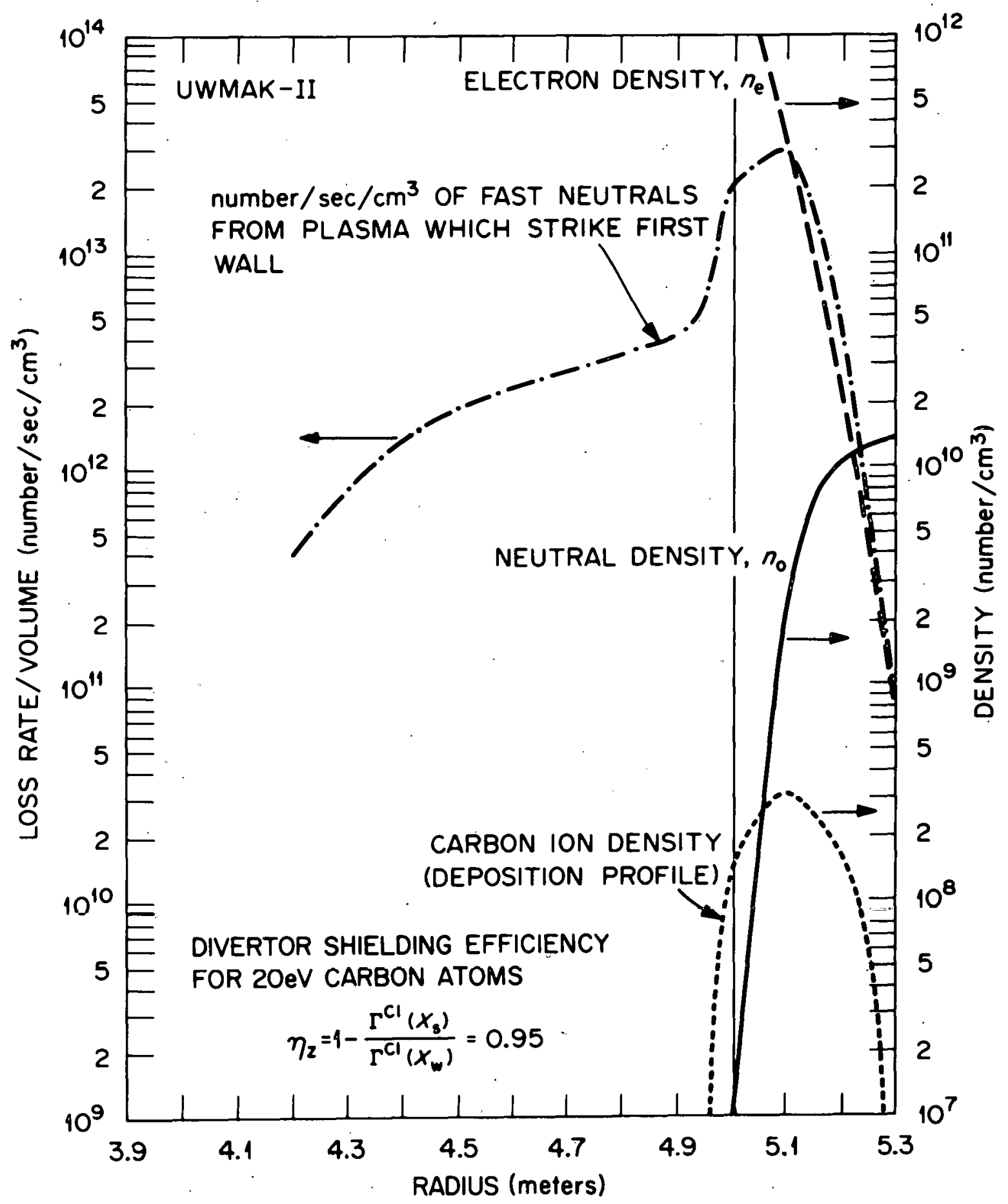

Fig. 2 . 


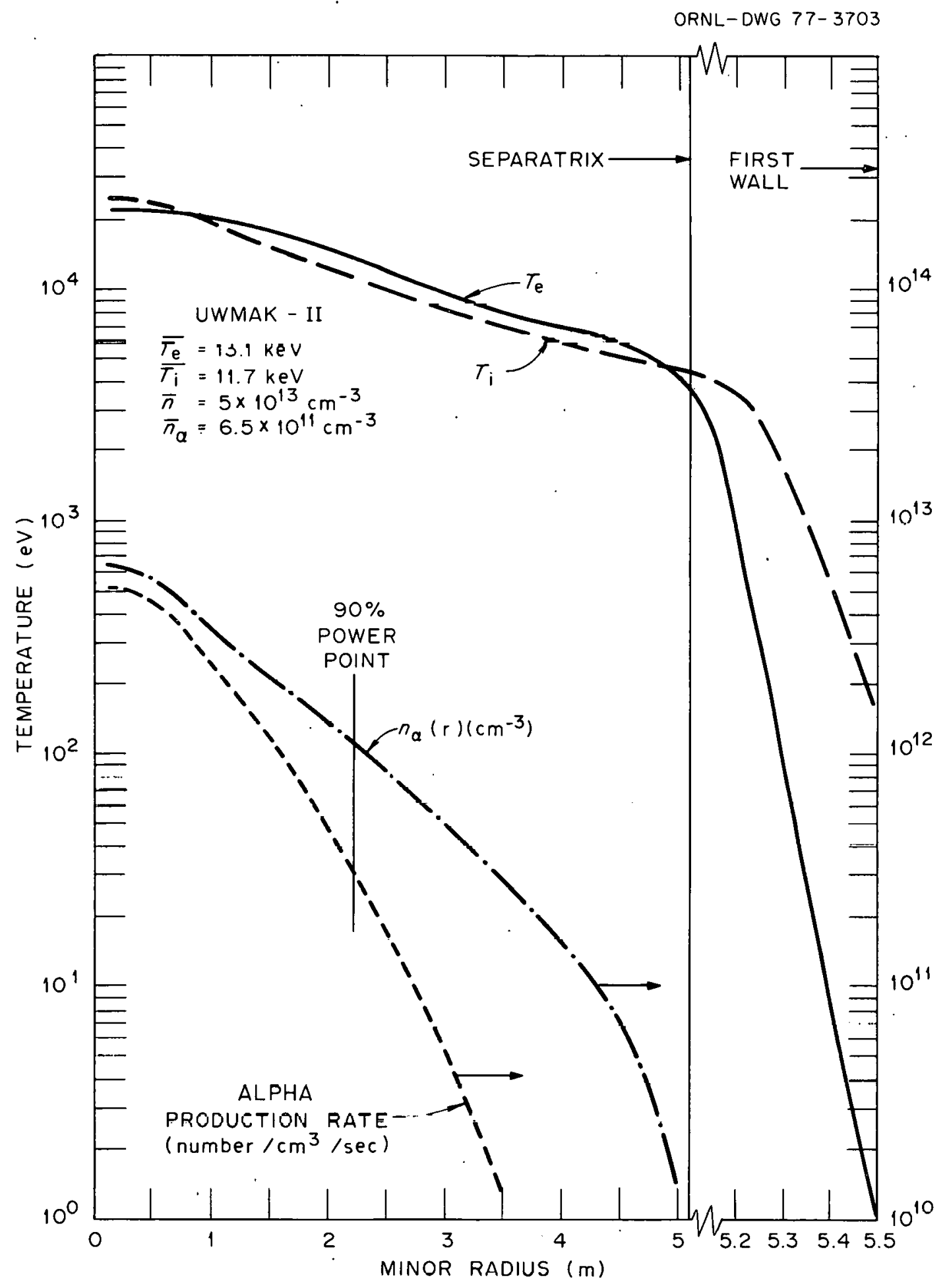

Fig. 3. 


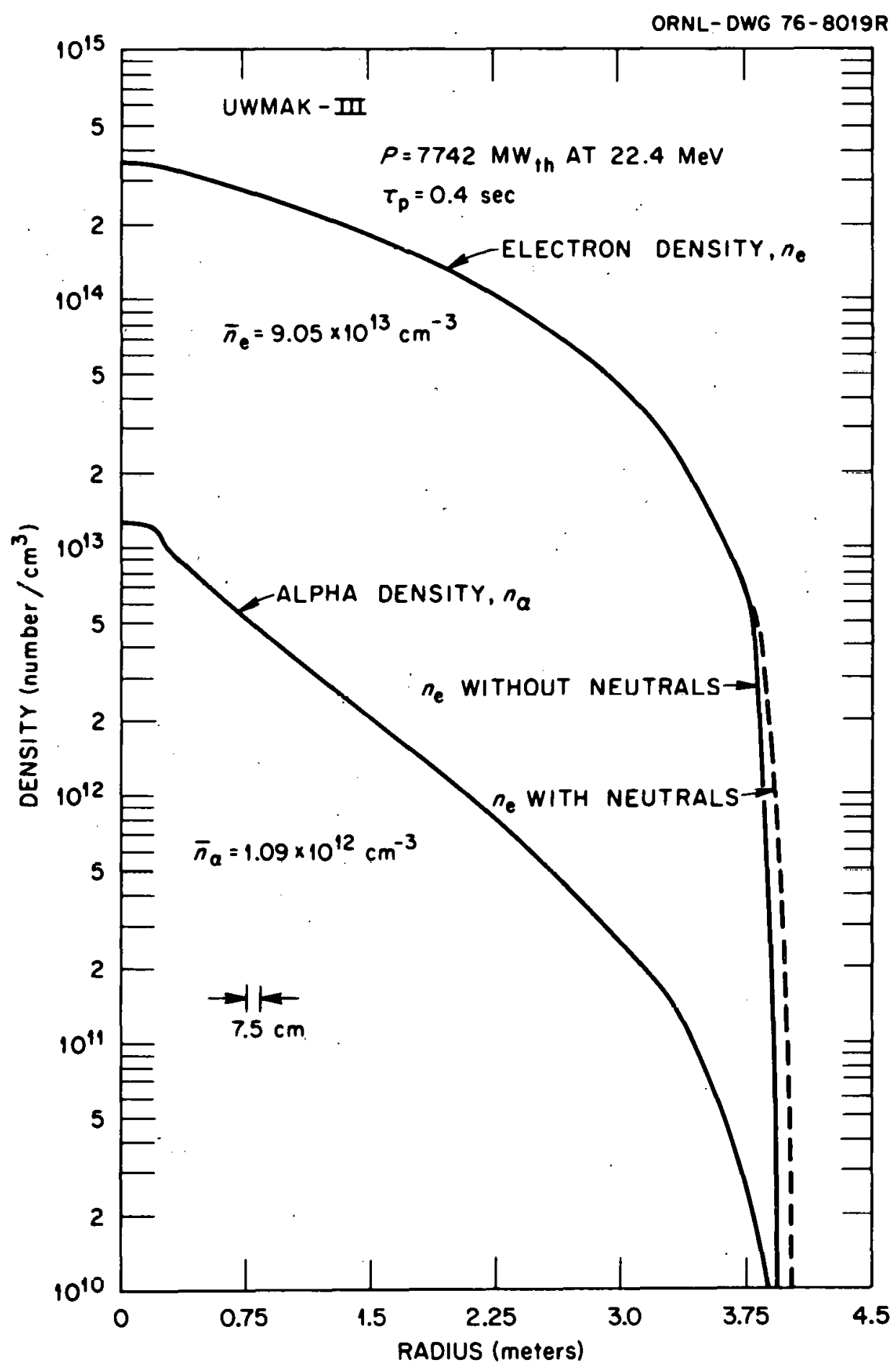

Fig. 4. 


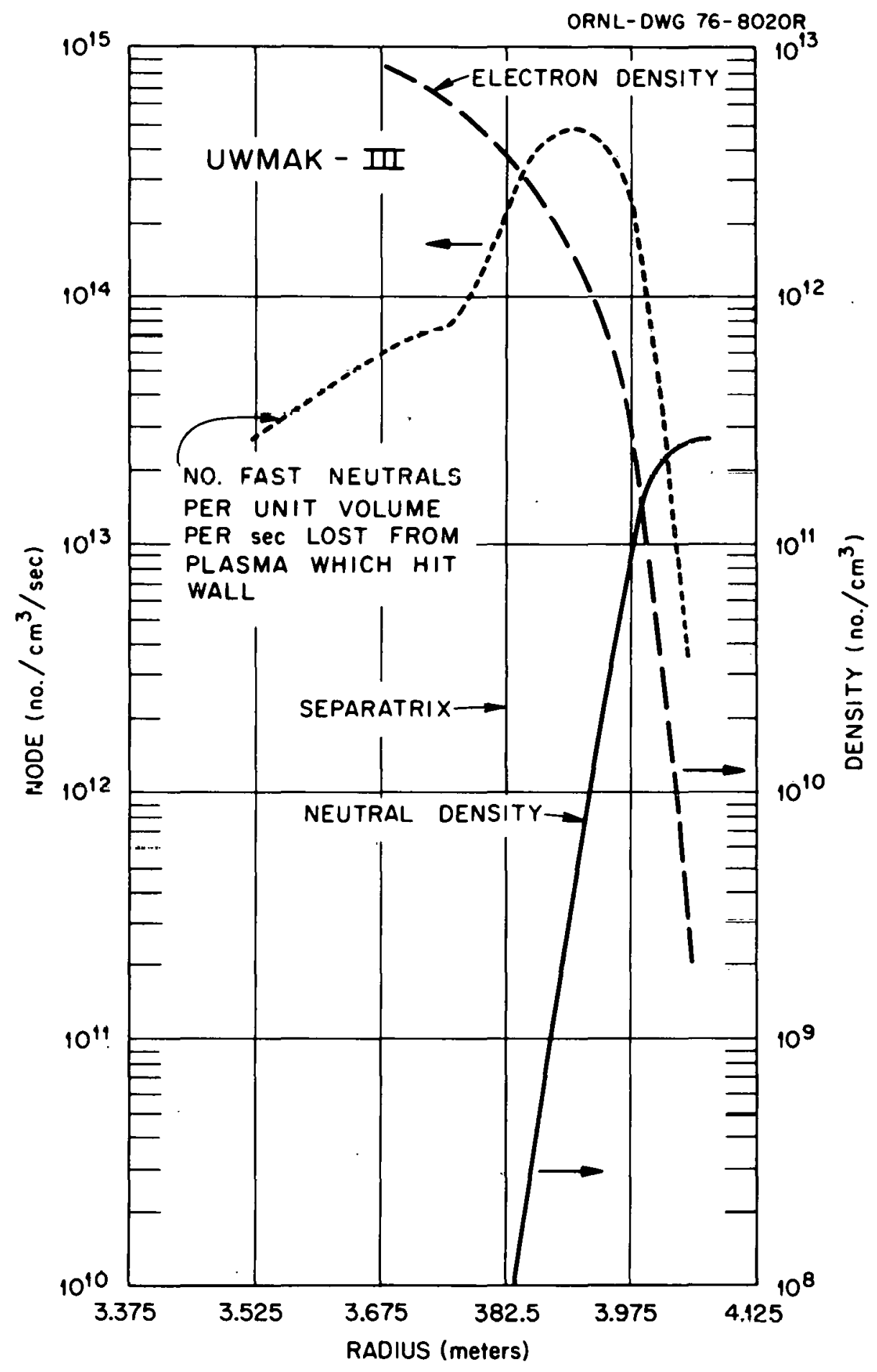

Fig. 5. 


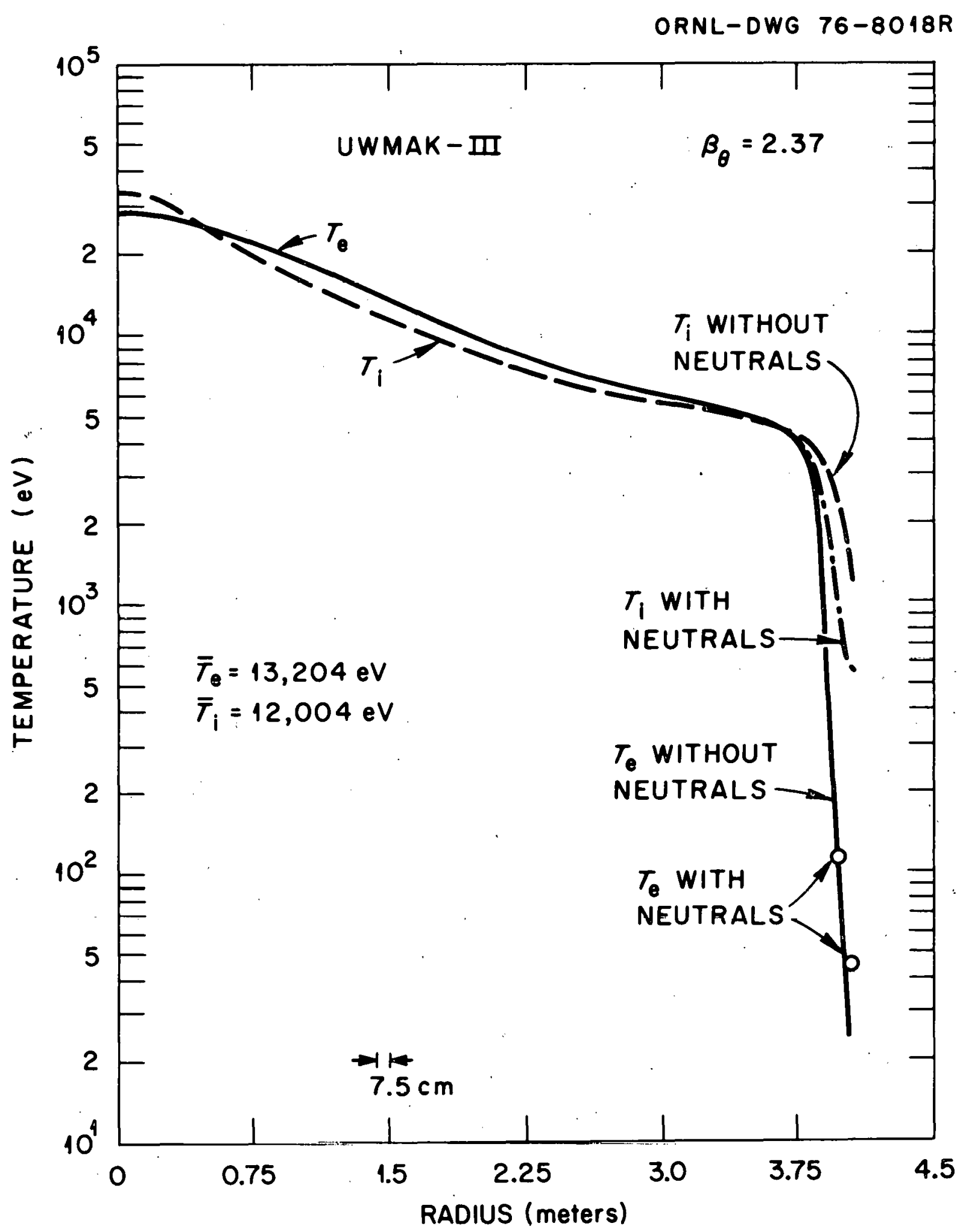

Fig. 6. 


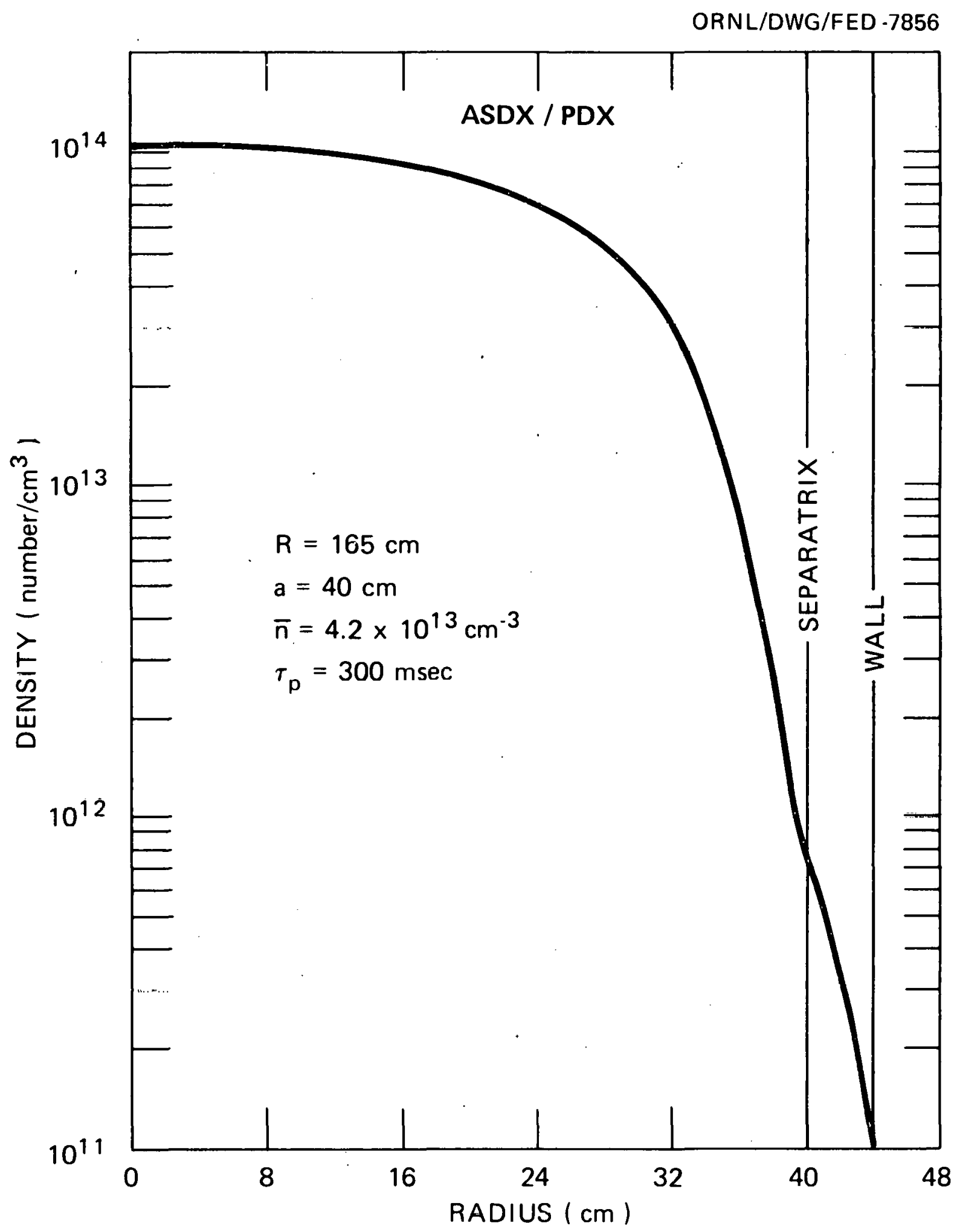

Fig. 7. 


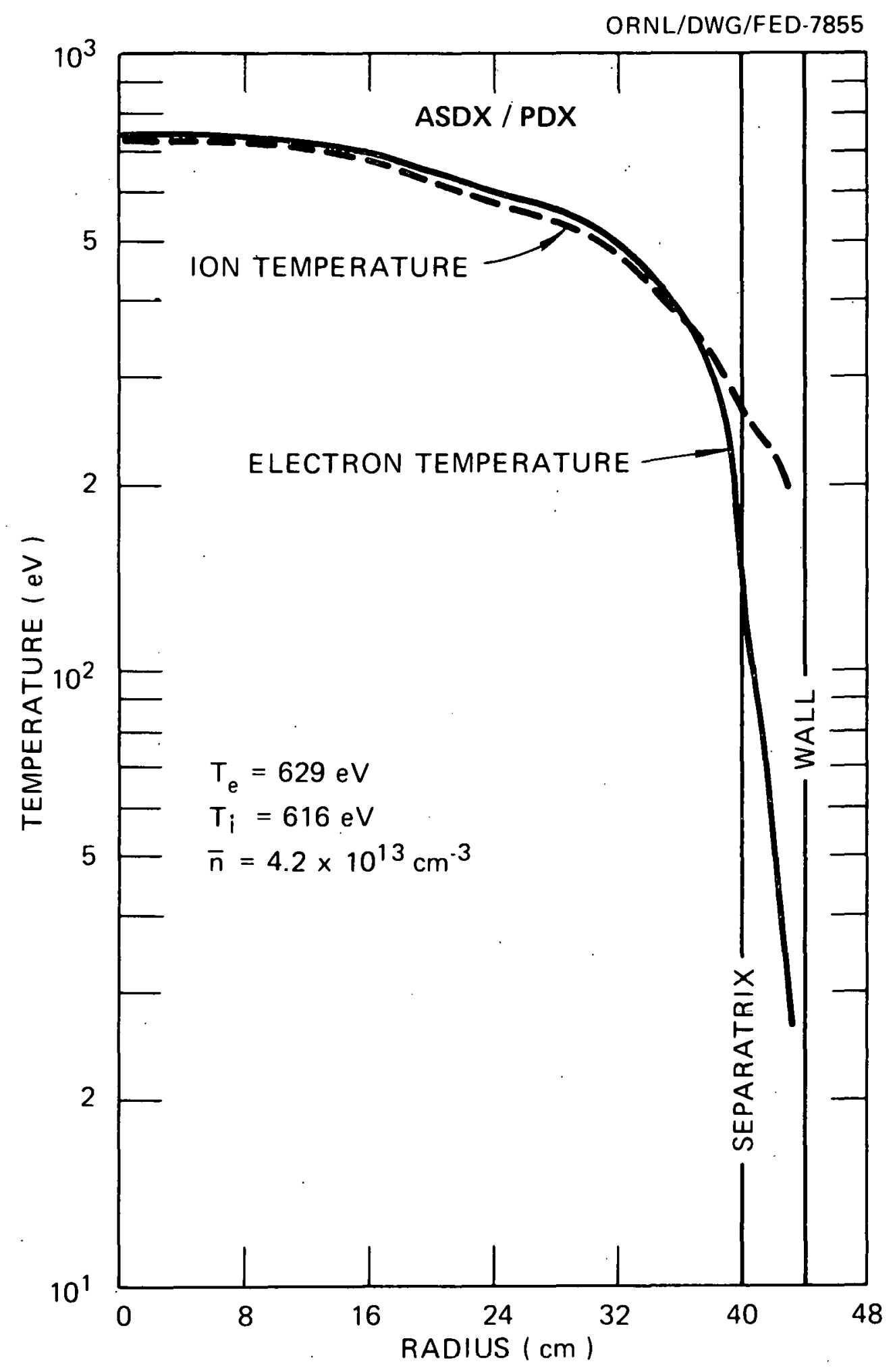

Fig. 8 . 


\section{THIS PAGE}

WAS INTENTIONALLY

LEFT BLANK 
ORNL/TM-6279

Dist. Category UC-20a, d, and $\mathrm{g}$

\section{INTERNAL DISTRIBUTION}

1. L. A. Berry

2. J. D. Callen

3. R. A. Dand 1

4. R. A. Dory

5. G. G. Kelley

6. H. H. Haselton

7. P. N. Haubenreich

8. M. S. Lube11

9. 0. B. Morgan

10. H. Postma

11. M. W. Rosenthal
12. J. Sheffield

13. D. Steiner

14-39. A. T. Mense

40-41. Laboratory Records Department

42. Laboratory Records, ORNL-RC

43. Document Reference Section

44-45. Central Research Library

46. Fusion Energy Division Library

47. Fusion Energy Division

Communications Center

48. ORNL Patent Office

\section{EXTERNAL DISTRIBUTION}

49. Bibliothek, Max-Planck Institute für Plasmaphysik, 8046 Garching bei München, Federal Republic of Germany

50. Bibliothèque, Service du Confinement des Plasmas, C.E.A., B.P. No. 6, 92, Fontenay-aux Roses (Seine), France

51. Lung Cheung, Department of Electronics, University Science Center, The Chinese University of Hong Kong, Shatin, N.T., Hong Kong

52. J. F. Clarke, Office of Fusion Energy, G-234, Department of Energy, Washington, DC 20545

53. D. Cohn, Massachusetts Institute of Technology, Cambridge, MA 02139

54. R. W. Conn, Fusion Technology Program, Nuclear Engineering Department, University of Wisconsin, Madison, WI. 53706.

55. CTR Library, c/o Alan F. Haught, United Technologies Research Laboratory, East Hartford, CT 06108

56. CTR Reading Room, c/o Allan N. Kaufman, Physics Department, University of California, Berkeley, CA 94720

57. Hatice Cullingford, Office of Fusion Energy, G-234, Department of Energy, Washington, DC 20545

58. J. Nar1 Davidson, School of Nuclear Engineering, Georgia Institute of Technology, Atlanta, GA 30332

59. Documentation S.I.G.N., Départment de la Physique du Plasma et de la Fusion Controlée, Association EURATOM-CEA sur la Fussion, Centre d'Études Nucléaires, B.P. 85, Centre du TRI, 38041 Grenoble, Cedex, France

60. W. R. Ellis, Office of Fusion Energy, G-234, Department of Energy, Washington, DC 20545

61. G. A. Emmert, Nuclear Engineering Department, University of Wisconsin, Madison, WI 53706

62. Harold K. Forsen, Exxon Nuclear Co., Inc., 777 106th Avenue, N.E., C-000777, Bellevue, WA $98009^{\circ}$ 
63. Harold P. Furth, Princeton Plasma Physics Laboratory, Princeton University, Forrestal Campus, P.0. Box 451, Princeton, NJ 08540

64. Roy W. Gould, California Institute of Technology, Mail Stop 116-81, Pasadena, CA 91125

65. Charles R. Head, Office of Fusion Energy, G-234, Department of Energy, Washington, DC 20545

66. Robert L. Hirsch, Exxon Research and Engineering, P.0. Box 101, Florham Park, NJ 07932

67. Raymond A. Huse, Manager, Research and Development, Pub1ic Service Gas and Electric Company, 80 Park Place, Newark, NJ 07101

68. T. Hsu, Office of Fusion Energy, G-234, Department of Energy, Washington, DC 205/5

69. V. E. Ivanov, Physical-Technical Institute of the Ukranian Academy of Sciences, Sukhumi, U.S.S.R.

70. D. L. Jassby, Princeton Plasma Physics Laboratory, P.0. Box 451, Princeton, NJ 08540

71. A. Kadisli, Offlie of Fuslon Energy, G-234, Department of Energy, Washington, DC 20545

72. L. M. Kovrizhnikh, Lebedev Institute of Physics, Academy of Sciences of the U.S.S.R., Leninsky Prospect 53, Moscow, U.S.S.R.

73. Guy Laval, Groupe de Physique Théorique, Ecole Polytechnique, 91 Palaiseau, Paris, France

74. Library, Centre de Recherches en Physique des Plasma, 21 Avenue des Bains, 1007, Lausanne, Switzerland

75. Library, Culham Laboratory, United Kingdom, Atomic Energy Authority, Abingdon, Oxon, OX14 3DB, United Kingdom

76. Library, FOM-Institut voor Plasma - Fysica, Rijnhuizen, Jutphaas, Netherlands

77. Library, Institute for Plasma Physics, Nagoya University, Nagoya, Japan 464

70. Liblaly, Lilerhallunal Cenlre fur Theurerical Physlcs, Irtesce, Italy

79. Library, Laboratorio Gas Ionizzati, Frascati, Italy

80. Dsumber G. Lominadze, Academy of Sciences of the Georgian S.S.R., 8 Dzerzhinski St., 38004, Tbilisi, U.S.S.R.

81. Oscar P. Manley, Office of Fusion Energy, G-234, Department of Energy, Washington, DC 20545

82. D. G. McAlees, Exxon Nuclear Co., Inc., Research and Technology Laser Enrichment Department, 2955 George Washington Way, Richland, WA 99352

83. J. E. McCune, School of Engineering, Department of Aeronautics and Astronautics, Bldg. 37-391, Massachusetts Institute of Technology, Cambridge, MA 02139

84. Claude Mercier, Service du Theorie des Plasmas, Centre d'Études Nucléaires, Fontenay-aux-Roses (Seine), France

85. K. G. Moses, Office of Fusion Energy, G-234, Department of Energy, Washington, DC 20545

86. Michael Murphy, Office of Fusion Energy, G-234, Department of Energy, Washington, DC 20545 
87. D. Pfirsch, Institute for Plasma Physics, 8046 Garching bei München, Federal Republic of Germany

88. Plasma Physics Group, Department of Engineering Physics, Australian National University, P.0. Box 4, Canberra A.C.T. 2600, Australia

89. Robert E. Price, Office of Fusion Energy, G-234, Department of Energy, Washington, DC 20545

90. A. Rogister, Institute for Plasma Physics, KFA, Postfach 1913, D-5170, Jülich 1, Federa1 Repub1ic of Germany

91. W. Sadowski, Office of Fusion Energy, G-234, Department of Energy, Washington, DC 20545

92. V. D. Shafranov, I. V. Kurchatov Institute of Atomic Energy, 46 Ulitsa Kurchatova, P.0. Box 3402, Moscow, U.S.S.R.

93. Yu. S. Sigov, Institute of Applied Mathematics of the U.S.S.R. Academy of Sciences, Miuskaya, Sq. 4, Moscow A-47, U.S.S.R.

94. W. M. Stacey, Jr., School of Nuclear Engineering, Georgia Institute of Technology, Atlanta, GA 30332

95. L. D. Stewart, Princeton Plasma Physics Laboratory, P.O. Box 451, Princeton, NJ 08540

96. J. B. Taylor, Culham Laboratory, U.K. Atomic Energy, Authority, Abingdon, Oxon, OX14 3DB, United Kingdom

97. Thermonuclear Library, Japan Atomic Energy Research Institute, Tokai, Naka, Ibaraki, Japan

98. Francisco Verdaguer, Director, Division of Fusion, Junta de Energia Nuclear, Madrid 3, Spain

99. K. M. Zwilsky, Office of Fusion Energy, G-234, Department of Energy, Washington, DC 20545

100. Director, Research and Technical Support Division, Department of Energy, Oak Ridge Operations, P.O. Box E, Oak Ridge, TN 37830

101-335. Given distribution as shown in TID-4500, Magnetic Fusion Energy (Distribution Category UC-20a, d, and g: Plasma Systems, Fusion Systems, and Theoretical Plasma Physics) 